\title{
Desenvolvimento de embutido fermentado por Lactobacillus probióticos: características de qualidade
}

\author{
Production of fermented sausage using probiotic Lactobacillus strains: quality characteristics
}

\author{
Renata Ernlund Freitas de MACEDO ${ }^{1 \star}$, Sérgio Bertelli PFLANZER Jr. ${ }^{1}$, \\ Nelcindo Nascimento TERRA ${ }^{2}$, Renato João Sossela de FREITAS ${ }^{3}$
}

\begin{abstract}
Resumo
Os probióticos têm sido largamente utilizados em produtos lácteos. Recentemente, seu uso em produtos cárneos tem despertado interesse, principalmente em embutidos fermentados consumidos na forma crua e sem aquecimento prévio. Verificou-se a influência da utilização de Lactobacillus casei, L. paracasei e L. rhamnosus sobre as características físico-químicas e sensoriais de embutido fermentado, bem como o desenvolvimento e a viabilidade das culturas no produto cárneo. Os embutidos foram processados em quatro tratamentos, sendo o primeiro tratamento usado como controle, enquanto os demais receberam a adição de uma espécie de Lactobacillus probiótico, seguindo procedimento de fabricação descrito para salame italiano por um período de 25 dias. A presença das culturas probióticas promoveu redução mais rápida do $\mathrm{pH}$ dos embutidos em relação ao tratamento controle, proporcionando gosto ácido mais intenso na avaliação sensorial, principalmente para cepa de L. rhamnosus. O crescimento de Staphylococcus xylosus da cultura starter sofreu redução com a adição dos probióticos, porém o desenvolvimento de Pediococcus pentosaceus não foi afetado. Os probióticos testados mostraram crescimento durante o processamento e permaneceram viáveis no produto final. Ficou demonstrada a viabilidade da utilização das culturas probióticas em embutido cárneo fermentado, principalmente L. casei e L. paracasei, preservando suas propriedades tecnológicas e sensoriais.

Palavras-chave: probióticos; Lactobacillus casei; Lactobacillus paracasei; Lactobacillus rhamnosus; salame.
\end{abstract}

\begin{abstract}
Probiotic Lactobacillus strains have been widely used in dairy products. Recently, attention has been directed to the use of probiotics in meat products, mainly in fermented sausages. The effect of the utilization of Lactobacillus casei, L. paracasei and L. rhamnosus strains on physicalchemical, microbiological and sensory quality of fermented sausage was evaluated. The sausages were processed in four batches: one was used as the control, while the other three batches received one of the probiotic strains each. The manufacturing procedure described for Italian salami with 25 days of fermentation and ripening was followed. The presence of probiotic Lactobacillus resulted in a faster $\mathrm{pH}$ decrease, which affected the taste of the probiotic sausages. There was an increase in acid notes, mostly in the sausage containing L. rhamnosus. The lactobacilli strains also decreased the growth of Staphylococcus xylosus; however, they did not affect the number of Pediococcus pentosaceus and the acceptability of the sausages in the sensory evaluation. All Lactobacillus strains showed an increase in viable cell count during manufacturing and this parameter remained high until the end of ripening. The viability of the utilization of probiotic Lactobacillus, especially $L$. paracasei and L. casei, in fermented sausage, maintaining the quality characteristics of the product, was demonstrated.

Keywords: probiotic; Lactobacillus paracasei; Lactobacillus casei; Lactobacillus rhamnosus; fermented sausage.
\end{abstract}

\section{Introdução}

A crescente preocupação dos consumidores em conhecer as características dos alimentos que consomem tem conduzido ao desenvolvimento de produtos que promovem a saúde e o bemestar, além de sua função de nutrição (TYÖPPÖNEN; PETÄJÄ; MATTILA-SANDHOLM, 2003). Esses alimentos que geram efeitos benéficos à saúde humana, aliados à ação nutricional são denominados funcionais. Seu efeito deve-se à adição de ingredientes ativos à remoção ou substituição de substâncias indesejáveis em sua composição (ERKKILÄ et al., 2001b).

Os probióticos são definidos como microrganismos vivos capazes de melhorar o equilíbrio microbiano intestinal produ- zindo efeitos benéficos à saúde do indivíduo (BRASIL, 2002). Segundo Leroy, Verluyten e Vuyst (2006) e Ammor e Mayo (2007), os probióticos necessitam ser ingeridos em quantidades suficientes para exercerem efeito benéfico sobre a fisiologia e saúde do hospedeiro. Ao consumo de probióticos estão associados vários efeitos benéficos à saúde, como o melhor trânsito intestinal dos alimentos, facilitando a digestão, o alívio dos sintomas de intolerância à lactose, aumento da resposta imune, redução dos episódios de diarréia, prevenção ou supressão de câncer de cólon e redução do colesterol sangüíneo (HEENAN et al., 2002).

Recebido para publicação em 24/1/2008

Aceito para publicação em 8/5/2008 (002174)

${ }^{1}$ Laboratório de Tecnologia de Produtos Agropecuários, Curso de Medicina Veterinária, Centro de Ciências Agrárias e Ambientais,

Pontifícia Universidade Católica do Paraná - PUCPR, BR 376, Km 14, CEP 83010-500, CP 129, São José dos Pinhais - PR, Brasil, E-mail: renata.macedo@pucpr.br

2 Centro de Ciências Rurais, Universidade Federal de Santa Maria - UFSM, Santa Maria - RS, Brasil

${ }_{3}^{3}$ Programa de Pós-Graduação em Tecnologia de Alimentos, Universidade Federal do Paraná - UFPR, Curitiba - PR, Brasil

${ }^{*}$ A quem a correspondência deve ser enviada 
Os microrganismos benéficos têm sido aplicados principalmente em bebidas lácteas, mas também em produtos à base de cereais, fórmulas para alimentação infantil, sucos de frutas e sorvetes, sendo ainda incipiente sua utilização em produtos cárneos (ERKKILÄ et al., 2001b; PAPAMANOLI et al., 2003; BEJDER, 2004).

$\mathrm{Na}$ indústria cárnea, o uso de probióticos mostra-se mais promissor nos produtos crus fermentados, haja vista serem fabricados com carne crua e consumidos sem prévio aquecimento, o que causaria a morte dos microrganismos (ERKKILÄ et al., 2001a; AMMOR; MAYO, 2007). Os embutidos cárneos, como o salame, são muitas vezes considerados produtos menos saudáveis devido ao seu conteúdo de gordura, aditivos e especiarias. Nesse sentido, a adição de probióticos a esses alimentos poderia trazer os benefícios à saúde associados às bactérias lácticas e contribuir para o aumento do consumo desses produtos por uma parcela da população preocupada com a manutenção da saúde.

Os embutidos fermentados, devido às suas características de baixo $\mathrm{pH}$ e atividade de água, além da presença de sais de cura e de outros microrganismos competidores, poderiam representar um ambiente desafiador para a sobrevivência de probióticos durante seu processo de fabricação (LEROY; VERLUYTEN; VUYST, 2006). Porém, diversos estudos têm demonstrado a viabilidade do uso de lactobacilos probióticos em produtos cárneos fermentados. Arihara et al. (1998) estudaram a aplicação de Lactobacillus gasseri para aumentar a segurança microbiológica de produto cárneo fermentado.

A utilização de L. rhamnosus e L. paracasei subsp. paracasei para a fermentação de produtos cárneos foi estudada por Sameshima et al. (1998). Erkkilä et al. (2001a) realizaram experimentos utilizando cepas probióticas de L. rhamnosus GG e cepas potencialmente probióticas de L. rhamnosus LC-705 e VTT-97800 para a fabricação de salames. Andersen (1998) demonstrou a possibilidade de fermentação de produto cárneo pela mistura de uma cultura starter tradicional Bactoferm T-SPX (Chr Hansen) e uma cultura potencialmente probiótica de L. casei LC-01 e pela mistura da mesma cultura starter com uma cultura de Bifidobacterium lactis Bb-12. Estudos relatados por Erkkilä et al. (2001a) mostram o potencial efeito probiótico de cepas de L. gasseri, L. rhamnosus, L. paracasei subsp. paracasei, L. casei e Bifidobacterium lactis utilizadas para a fermentação de salame.

A inibição da colonização e virulência de Listeria monocytogenes no trato intestinal de ratos pelo consumo de produto cárneo fermentado adicionado de culturas starter, culturas probióticas e L. monocytogenes foi testada por Mahoney e Henriksson (2003). Os resultados mostraram que a cultura starter composta por Pediococcus pentosaceus e Staphylococcus xylosus e as culturas probióticas compostas por L. acidophilus, L. paracasei e bactérias do gênero Bifidobacterium foram capazes de inibir o crescimento de Listeria durante sua passagem pelo trato gastrintestinal. Verificou-se também um possível efeito protetor da massa do salame sobre a mucosa intestinal, por envolver a bactéria patogênica em sua matriz, não permitindo a adesão e colonização do intestino, havendo eliminação do patógeno nas fezes.
O objetivo do presente trabalho foi verificar a influência da adição das espécies probióticas de Lactobacillus casei, Lactobacillus paracasei e Lactobacillus rhamnosus sobre as características físico-químicas e sensoriais de embutido fermentado, bem como seu desenvolvimento e viabilidade no produto cárneo.

\section{Material e métodos}

\subsection{Microrganismos}

Nos embutidos fermentados produzidos no presente trabalho utilizou-se como cultura starter a cultura comercial Bactoferm T-SPX contendo os microrganismos Staphylococcus xylosus DD-34 e Pediococcus pentosaceus PC-01 (Chr Hansen, Dinamarca).

Como culturas probióticas foram testadas as seguintes espécies de Lactobacillus: L. casei (LC 01 Chr Hansen, Dinamarca) obtida sob a forma liofilizada, $L$. paracasei ssp. paracasei (ATCC 10746/ CCT 0566) e L. casei ssp. rhamnosus (ATCC 7469/CCT 6645) obtidas sob a forma reativada em ágar MRS da Coleção de Culturas Tropicais da Fundação André Tosello, Campinas-SP.

De acordo com o catálogo de culturas da American Type Culture Collection (ATCC, 2005), a cultura de L. casei ssp. rhamnosus ATCC 7469 está classificada como L. rhamnosus e foi descrita neste trabalho como uma subespécie de L. casei, pois foi fornecida pela Coleção de Culturas Tropicais da Fundação André Tosello com a referida denominação.

\subsection{Processamento dos embutidos fermentados}

Para a fabricação dos embutidos cárneos utilizou-se a formulação descrita na Tabela 1.

Para a formulação dos embutidos, a quantidade de matériaprima, cloreto de sódio, açúcares e condimentos baseou-se em formulações descritas por Terra (1998) e Terra, Fries e Terra (2004). Para a adição do fixador utilizou-se a dosagem

Tabela 1. Formulação básica utilizada na fabricação de embutido cárneo adicionado de culturas probióticas.

\begin{tabular}{lc}
\hline Matérias-primas e ingredientes & Quantidade \\
\hline Carne suína & $56,31 \%$ \\
Carne bovina & $19 \%$ \\
Toucinho & $19 \%$ \\
Sal (cloreto de sódio) & $3,0 \%$ \\
Glicose & $0,5 \%$ \\
Sacarose & $0,5 \%$ \\
Alho em pó & $0,3 \%$ \\
Pimenta branca & $0,2 \%$ \\
Noz moscada & $0,02 \%$ \\
Nitrito de sódio & $0,015 \%$ \\
Nitrato de sódio & $0,005 \%$ \\
Fixador (acelerador de cura) & $1 \%$ \\
Cultura starter comercial TSPX & $0,15 \%$ \\
(Chr Hansen) & \\
Cultura probiótica & Variável para cada tratamento \\
\hline
\end{tabular}


recomendada pelo fabricante. A quantidade de cultura starter utilizada baseou-se no número de células viáveis presentes na cultura comercial liofilizada necessário para atingir na massa do embutido o valor mínimo de $1 \times 10^{8}$ UFC.g $^{-1}$.

O preparo da massa iniciou-se pela moagem das matériasprimas cárneas em disco de aço inox de $5 \mathrm{~mm}$ para a carne bovina e em disco de $8 \mathrm{~mm}$ para a carne suína. A carne bovina deve ser moída em chapa mais fina, pois suas fibras apresentam maior espessura e resistência em comparação às fibras da carne suína. O toucinho congelado foi picado em cubos com tamanho de $0,5 \mathrm{~cm}$. Procedeu-se a mistura manual das matérias-primas cárneas e de parte do cloreto de sódio para a obtenção de consistência pastosa e promoção de liga na massa, obtida pela extração completa das proteínas miofibrilares que respondem pela união dos fragmentos de carne no produto final. Posteriormente, foram adicionados à massa toucinho, pimenta branca, alho em pó, noz moscada, glicose, sacarose e o restante do cloreto de sódio. Os sais de cura, nitrito e nitrato de sódio e o fixador foram adicionados à massa previamente diluídos em água destilada para facilitar sua mistura, sendo o fixador adicionado em seguida aos sais de cura (TERRA, 1998; GARCIA; GAGLEAZZI; SOBRAL, 2000).

A cultura starter composta de P. pentosaceus e S. xylosus foi adicionada à massa em concentração celular superior a $3,2 \times 10^{10}$ UFC. $^{-1}$ de inóculo, ao final da mistura, após prévia ativação em água não clorada por 30 minutos. As culturas probióticas foram adicionadas à massa após a adição da cultura starter.

O embutimento das massas foi realizado em embutideira manual (JAMAR) utilizando tripa artificial de colágeno reconstituído com calibre de $45 \mathrm{~mm}$ previamente embebida em solução de ácido láctico a $1 \%$ por 15 minutos para promover desinfecção e facilitar sua aderência à massa (NASSU; BESERRA; GONÇALVES, 2002; TERRA; FRIES; TERRA, 2004).

No presente trabalho, foram realizados quatro tratamentos que variaram quanto ao tipo da cultura bacteriana adicionada ao embutido cárneo. O Tratamento 1, denominado de tratamento controle, recebeu adição apenas da cultura starter comercial, enquanto que nos demais tratamentos, os embutidos receberam além da cultura starter, a adição de diferentes espécies de Lactobacillus potencialmente probióticos, de acordo com a seguinte descrição:

- Tratamento 1 (controle): cultura starter TSPX contendo Pediococcus pentosaceus e Staphylococcus xylosus;

- Tratamento 2: cultura starter TSPX + cultura pura de Lactobacillus casei;

- Tratamento 3: cultura starter TSPX + cultura pura de Lactobacillus casei ssp. rhamnosus; $e$

- Tratamento 4: cultura starter TSPX + cultura pura de Lactobacillus paracasei ssp. paracasei.

\section{Preparação dos inóculos de culturas probióticas}

Considerando-se que o número de células viáveis das culturas bacterianas recomendado para adição à massa cárnea seja dois ciclos logarítmicos superior ao número de células da microbiota contaminante da carne e que o número máximo aceitável de microrganismos contaminantes na carne é de $10^{6} \mathrm{UFC}^{-g^{-1}}$ (TERRA, 1998), a quantidade de culturas probióticas adicionada à massa dos embutidos deve ser de no mínimo $10^{8}$ UFC.g $^{-1}$. Obedecendo a essa proporção e considerando a quantidade total de 3.000 g de massa cárnea utilizada para cada tratamento, o número de células viáveis das culturas probióticas necessário para a inoculação da massa cárnea seria $3 \times 10^{11}$ UFC. Para obter a referida quantidade de células viáveis de bactérias probióticas no inóculo tornou-se necessária a utilização do volume inicial de $1.000 \mathrm{~mL}$ de inóculo, haja vista que na contagem do número de células viáveis das cepas probióticas puras em caldo MRS obteve-se valor de $3 \times 10^{8} \mathrm{UFC} . \mathrm{mL}^{-1}$. Devido ao grande volume de inóculo necessário, as células bacterianas foram concentradas por centrifugação previamente à inoculação na massa cárnea.

As cepas puras de L. casei, L.casei ssp. rhamnosus e Lactobacillus paracasei ssp. paracasei foram pré-ativadas em $10 \mathrm{~mL}$ de caldo MRS com incubação a $37^{\circ} \mathrm{C}$ por 48 horas. Após a pré-ativação, alíquotas de $3 \mathrm{~mL}$ de cada cultura foram semeadas em $1.000 \mathrm{~mL}$ de caldo MRS com posterior incubação em estufa bacteriológica a $37^{\circ} \mathrm{C}$ por 48 horas. Após esse período, procedeu-se a centrifugação do volume total de caldo contendo as culturas ativadas em centrífuga refrigerada (EPPENDORF $5810 \mathrm{R})$ a $15^{\circ} \mathrm{C}$ com rotação de $3.500 \mathrm{rpm}$ por 15 minutos.

O sobrenadante foi descartado e o precipitado adicionado à massa dos embutidos após a adição de todos os demais ingredientes e da cultura starter. Do volume total de precipitado de cada cultura, tomou-se $2 \mathrm{~mL}$ para a contagem do número de células viáveis dos inóculos. A concentração celular de L. casei obtida após centrifugação e adicionada ao Tratamento 2 foi de $7,5 \times 10^{10}$ UFC. $\mathrm{mL}^{-1}$ de inóculo. Para L. casei ssp. rhamnosus obteve-se número de células viáveis de $6,5 \times 10^{10}$ UFC.mL $\mathrm{mL}^{-1}$ (Tratamento 3) e para L. paracasei $7,5 \times 10^{10}$ UFC. $\mathrm{mL}^{-1}$ (Tratamento 4).

\section{Condições de temperatura e umidade relativa do ar na câmara de maturação}

Para cada tratamento obteve-se em média 20 peças de embutido cárneo, com comprimento aproximado de $12 \mathrm{~cm}$. Os embutidos foram maturados por 25 dias em câmara de incubação B.O.D. (FANEM, MDL 347 CD) com temperatura inicial de $25^{\circ} \mathrm{C}$ e umidade relativa do ar de $89 \%$, as quais sofreram redução gradativa para permitir a secagem do produto (Tabela 2).

A temperatura inicial de fermentação dos embutidos influencia sua qualidade final. Temperaturas acima de $26{ }^{\circ} \mathrm{C}$ podem ocasionar problemas relacionados à segurança microbiológica do produto, além de excessiva acidificação e fusão das gorduras (NASSU; BESERRA; GONÇALVES, 2002).

\subsection{Análises físico-químicas, microbiológicas e sensoriais}

As modificações físico-químicas e microbiológicas ocorridas nos embutidos durante a maturação foram avaliadas no 1, 3, $5,7,11,14,21$ e $25^{\circ}$ dias. As análises físico-químicas realizadas nas amostras coletadas para cada tratamento foram: atividade 
Tabela 2. Condições de temperatura e umidade relativa do ar utilizadas na câmara de incubação durante o período de maturação dos embutidos fermentados.

\begin{tabular}{ccc}
\hline $\begin{array}{c}\text { Tempo de maturação } \\
\text { (dias) }\end{array}$ & Temperatura $\left({ }^{\circ} \mathrm{C}\right)$ & $\begin{array}{c}\text { Umidade relativa do } \\
\text { ar (\%) }\end{array}$ \\
\hline 1 & 25 & 89 \\
2 & 24 & 89 \\
3 & 23 & 88 \\
4 & 22 & 88 \\
5 & 21 & 87 \\
6 & 20 & 86 \\
7 & 18 & 80 \\
8 & 18 & 77 \\
9 & 18 & 75 \\
$\downarrow$ & $\downarrow$ & $\downarrow$ \\
25 & 18 & 75 \\
\hline
\end{tabular}

de água, acidez titulável, umidade, $\mathrm{pH}$, perda de peso e perda de diâmetro. Para verificar a viabilidade das culturas bacterianas adicionadas foi realizada a contagem de Lactobacillus para os Tratamentos 2,3 e 4 e a contagem de P. pentosaceus e S. xylosus para todos os tratamentos. A avaliação sensorial foi realizada para todos os tratamentos após 25 dias de maturação dos embutidos cárneos.

Os valores de $\mathrm{pH}$ foram determinados por processo eletrométrico em potenciômetro digital devidamente calibrado com soluções tampão de pH 7,0 e 4,0, com sonda de perfuração, mediante leituras diretas nos embutidos, evitando-se o contato da sonda com a gordura das amostras (TERRA; BRUM, 1988).

O teor de ácidos livres nos embutidos fermentados foi determinado pelo método titulométrico com solução de hidróxido de sódio 0,1 N (TERRA; BRUM, 1988).

A atividade de água dos embutidos foi verificada utilizandose aparelho medidor de atividade de água (AQUALAB CX-2) por medida direta nas amostras previamente trituradas e mantidas à temperatura ambiente de $21^{\circ} \mathrm{C}$.

A umidade dos embutidos fermentados foi determinada pelo método gravimétrico com dessecação em estufa a $105^{\circ} \mathrm{C}$, conforme metodologia descrita pela AOAC (2000).

A perda de peso dos embutidos durante a maturação e secagem foi determinada pelo método gravimétrico, mediante a pesagem de duas peças de embutido de cada tratamento antes da maturação e após cada tempo de amostragem até o momento do envase a vácuo. Os resultados foram expressos em porcentagem de perda de peso.

O diâmetro de duas peças de embutido de cada tratamento foi medido com uso de régua graduada antes da maturação e após cada tempo de amostragem até o final da secagem, sendo os resultados expressos em porcentagem de redução de diâmetro.

O procedimento de preparo das amostras de embutidos para as contagens microbiológicas foi realizado conforme a metodologia descrita por Brasil (2003), recomendada para controle de produtos de origem animal e água. Seguindo os procedi- mentos, as amostras foram diluídas em água peptonada a $0,1 \%$, acondicionadas em sacos plásticos estéreis e homogeneizadas em homogeneizador stomacher por 60 segundos, executando-se diluições subseqüentes até a concentração desejada.

A contagem de $P$. pentosaceus, bactéria láctica da cultura starter adicionada aos embutidos, foi realizada pela semeadura em profundidade das amostras homogeneizadas e diluídas em água peptonada estéril a $0,1 \%$ até a concentração desejada em placas de Petri com ágar MRS adicionado de $10 \mathrm{mg}$ de tetraciclina (SIGMA Chemical Co) por litro do meio para inibição do crescimento de Lactobacillus.

Após a semeadura, as placas invertidas foram incubadas em estufa bacteriológica a $37^{\circ} \mathrm{C}$ por 48 horas e o resultado da contagem expresso em UFC. ${ }^{-1}$ de amostra (SWANSON et al., 1992; SILVA; JUNQUEIRA; SILVEIRA, 2001).

A contagem dos Lactobacillus adicionados como culturas probióticas aos embutidos fermentados foi realizada em ágar MRS (DE MAN; ROGOSA; SHARPE, 1960; CARR; CHILL; MAIDA, 2002) com incubação a $37^{\circ} \mathrm{C}$ por 48 horas. Essas condições de composição do meio de cultura e incubação permitem o crescimento concomitante de Lactobacillus e de Pediococcus da cultura starter. Dessa forma, o resultado da contagem de Lactobacillus foi calculado como a diferença entre a contagem total de bactérias lácticas em ágar MRS puro e a contagem de Pediococcus em ágar MRS adicionado de $10 \mathrm{mg} . \mathrm{L}^{-1}$ de tetraciclina.

A contagem de $S$. xylosus, bactéria integrante da cultura starter, foi realizada pela semeadura das diluições decimais das amostras em placas de Petri com ágar Baird Parker incubadas a $37^{\circ} \mathrm{C}$ por 48 horas e o resultado expresso em UFC. $\mathrm{g}^{-1}$ (ERKKIL $\ddot{\mathrm{A}}$ et al., 2001a; ERKKILÄ et al., 2001b).

Como indicativo das condições higiênico-sanitárias de processamento dos embutidos e da ação inibitória das culturas bacterianas adicionadas aos embutidos sobre a flora contaminante foram realizadas a contagem de coliformes totais e a contagem de Escherichia coli.

As contagens foram executadas pelo método Petrifilm Coliformes (SILVA; JUNQUEIRA; SILVEIRA, 2001) em placas Petrifilm (3M) com incubação a $37^{\circ} \mathrm{C}$ por 48 horas, onde as colônias de coliformes totais mostram-se vermelhas associadas a bolhas de gás, e as colônias de Escherichia coli mostram-se azuis ou vermelho-azuladas com bolhas de gás. A principal vantagem das placas de Petrifilm em relação aos métodos convencionais é a sua conveniência, pois estão prontas para o uso, eliminando as etapas necessárias de preparação dos meios de cultura e vidrarias, ocupam menos espaço em incubadoras, geladeiras, armários, autoclaves, têm descarte mais fácil, não quebram, não derramam e podem ser congeladas para contagem posterior ou reanálise (SANT’ANA; CONCEIÇÃO; AZEREDO, 2002).

A opção pela contagem de Escherichia coli como indicador de contaminação fecal e não pela contagem de coliformes termotolerantes baseou-se no fato de que a contagem específica de Escherichia coli permite determinação mais exata da incidência de contaminação fecal (SILVA; JUNQUEIRA; SILVEIRA, 2001). 
As amostras para avaliação sensorial foram preparadas mediante o corte transversal das peças de embutidos, em forma de fatias finas com espessura média de três milímetros, descartando-se as extremidades. As amostras de cada tratamento foram apresentadas a uma equipe de 18 provadores semitreinados, habituados ao consumo de embutidos fermentados, distribuídas em pratos de polietileno codificados aleatoriamente com números de três dígitos.

As características avaliadas foram cor, sabor, aroma, textura, gosto ácido e aspecto, utilizando escala hedônica de 9 pontos, cuja pontuação 1 correspondia à denominação ruim, fraco ou suave, a pontuação 5 à denominação indiferente e a pontuação 9 à denominação bom, forte ou firme, dependendo do atributo avaliado. Os valores obtidos nas amostras para cada característica avaliada foram analisados estatisticamente por análise de variância (ANOVA) e teste de comparação de médias, utilizando nível de significância de 5\% (MORAES, 1990; CHAVES; SPROESSER, 1993; DUTCOSKI, 2007).

\subsection{Análise estatística}

Os valores obtidos nas análises realizadas nos embutidos fermentados dos Experimentos 1, 2 e 3 foram submetidos ao cálculo de média, desvio padrão e análise de variância, utilizando função específica do programa Excel da Microsoft Corporation e ao teste de Tukey para a comparação de médias com significância a 5\% (GOMES, 1990).

\section{Resultados e discussão}

\subsection{Determinações físico-químicas}

Durante as diferentes fases do processamento dos embutidos fermentados, três grandes grupos de substâncias presentes influenciam os valores de $\mathrm{pH}$ : os ácidos orgânicos oriundos da fermentação dos açúcares, os compostos básicos resultantes da proteólise gerada pelos microrganismos ou pelas próprias enzimas tissulares e os ácidos orgânicos procedentes das gorduras (CHAGAS, 1998).

A evolução do $\mathrm{pH}$ e da acidez nos embutidos fermentados durante o período de maturação e secagem está apresentada na Figura 1.

Verificou-se que os embutidos pertencentes aos Tratamentos 2,3 e 4 , que receberam a adição de culturas probióticas, mostraram menores valores de $\mathrm{pH}$ e maiores valores de acidez em relação ao tratamento controle durante 25 dias de processamento, havendo diferença estatística significativa de 5\% para os valores de $\mathrm{pH}$ entre o tratamento controle e os demais tratamentos. Para a acidez não foi verificada diferença estatística significativa entre os tratamentos $(\mathrm{p} \leq 0,05)$.

$\mathrm{O} \mathrm{pH}$ inicial (tempo 0) observado para os embutidos dos Tratamentos 2, 3 e 4 foi ligeiramente inferior ao do tratamento controle em decorrência da acidez do caldo utilizado como inóculo das culturas probióticas.

Sameshima et al. (1998) estudaram a queda do $\mathrm{pH}$ em salames adicionados de L. rhamnosus e L. paracasei ssp. paracasei
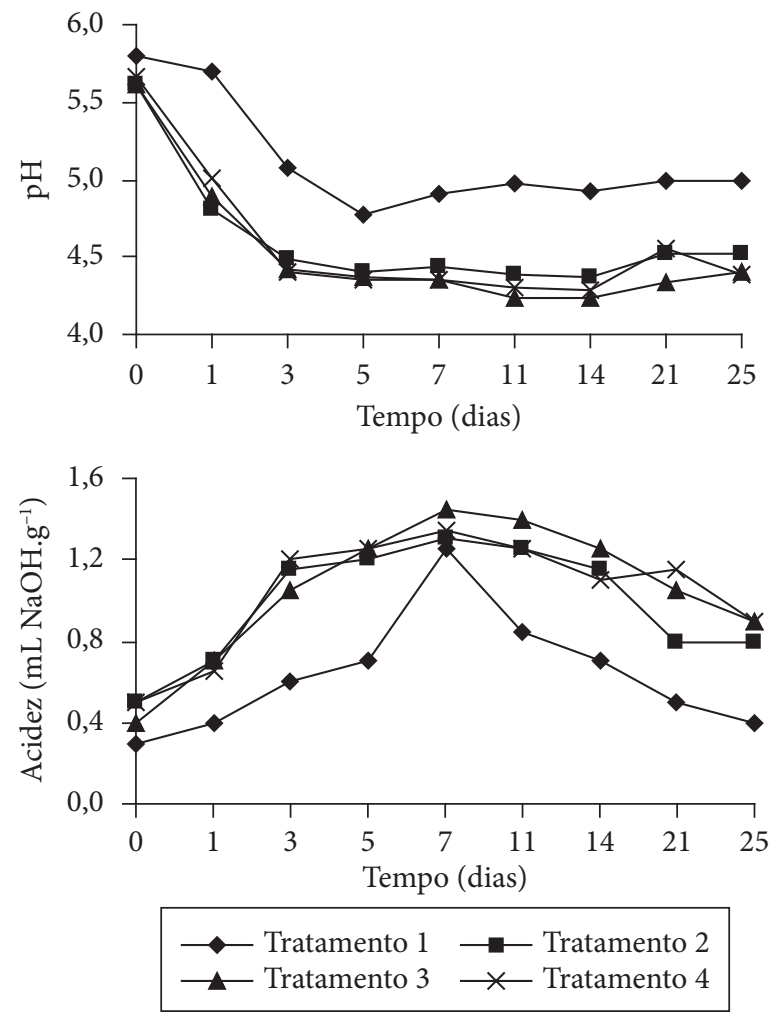

Figura 1. Variações de pH e acidez dos embutidos fermentados adicionados de culturas probióticas durante 25 dias de maturação e secagem. Tratamento 1: controle (starter); Tratamento 2: Lactobacillus casei + starter; Tratamento 3: Lactobacillus casei ssp. rhamnosus + starter; e Tratamento 4: Lactobacillus paracasei ssp. paracasei + starter.

e verificaram que após 24 horas de fermentação, o pH dos embutidos situou-se entre 5,0 e 5,2. Esses valores mostram-se semelhantes ao valor de 5,01 encontrado para o Tratamento 4 (adicionado de $L$. paracasei) e ligeiramente superior ao valor de 4,89 encontrado para o Tratamento 3 (adicionado de L. rhamnosus).

Nos primeiros três dias de maturação verificou-se rápida queda do $\mathrm{pH}$ dos embutidos com valores que variaram entre 5,08 e 4,40. Os embutidos adicionados de L. casei, L. rhamnosus e L. paracasei mostraram valores de $\mathrm{pH}$ de $4,48,4,42$ e 4,40 no terceiro dia de fermentação, respectivamente, apresentando resultados próximos ao valor de $\mathrm{pH} 4,4$ encontrado por Sameshima et al. (1998) em salames adicionados de L. rhamnosus e L. paracasei para o mesmo período de maturação. Os referidos autores também verificaram que esses baixos valores de $\mathrm{pH}$ produzidos pelas culturas de L. rhamnosus e $L$. paracasei foram capazes de inibir o crescimento de Staphylococcus aureus nos salames.

A queda do $\mathrm{pH}$ nos embutidos fermentados, para valores próximos a 5,0 nos primeiros dias de fermentação, torna o ambiente protegido contra a ação de bactérias gram negativas indesejáveis; constituindo a base para sua segurança microbiológica (LÜCKE, 2000; ERKKILÄ et al., 2001b; TYÖPPÖNEN et al., 2003). 
A redução do pH do salame para níveis próximos a 5,0 objetiva alcançar o ponto isoelétrico das proteínas miofibrilares da carne, provocando perda de água e obtenção de textura no produto (CAMPOS, 2002).

A partir do sétimo dia de fabricação, o $\mathrm{pH}$ observado no tratamento controle sofreu ligeiro aumento, mantendo-se próximo a 5,0 até o final da maturação e secagem, enquanto que os valores de $\mathrm{pH}$ dos embutidos com culturas probióticas sofreram pequenas oscilações ao longo dos 25 dias de processamento, variando entre 4,55 e 4,24. De acordo com Terra, Fries e Terra (2004), a partir do sétimo dia de fabricação, os valores de $\mathrm{pH}$ sofrem aumento devido às reações de descarboxilação e desaminação de aminoácidos, que liberam amônia no meio, alcalinizando-o. Porém, o $\mathrm{pH}$ pode sofrer nova redução devido à lipólise que libera ácidos graxos livres no meio.

Erkillä et al. (2001a) observaram que no sétimo dia de maturação de salames fermentados com três diferentes cepas de L. rhamnosus, sem o uso de cultura starter, os valores de $\mathrm{pH}$ variaram entre 4,9 e 5,1, situando-se acima do $\mathrm{pH}$ obtido para o Tratamento 3 (starter + L. rhamnosus). O valor de $\mathrm{pH}$ obtido no Tratamento 3 foi menor em decorrência da presença de $P$. pentosaceus na cultura starter utilizada, que por tratar-se de bactéria láctica, produz ácido láctico no meio e, conseqüentemente, provoca a queda de $\mathrm{pH}$.

Os embutidos pertencentes aos quatro tratamentos mostraram aumento da acidez até o sétimo dia de fermentação. A partir do décimo primeiro dia, observou-se redução gradativa da acidez, que assim permaneceu até o final da fabricação, coincidindo com o ligeiro aumento de $\mathrm{pH}$ observado para o mesmo período.

Ao final do processamento, o embutido controle obteve $\mathrm{pH}$ próximo a 5,0 e acidez de $0,4 \mathrm{~mL}$ de $\mathrm{NaOH} .100 \mathrm{~g}^{-1}$, ao passo que nos tratamentos com culturas probióticas os valores de pH ficaram próximos a 4,5 e de acidez entre 0,8 e $0,9 \mathrm{~mL}$ de $\mathrm{NaOH} .100 \mathrm{~g}^{-1}$, demonstrando atividade fermentativa das culturas probióticas sobre os açúcares do meio. Muthukumarasamy e Holley (2006) observaram que em salames adicionados de L. reuteri com ou sem microencapsulação por alginato de sódio, os embutidos alcançaram valores médios de $\mathrm{pH}$ de 4,74 e atividade de água de 0,89 após 27 dias de processamento.

A porcentagem de umidade e a atividade de água (Aw) são determinações utilizadas para medir o teor de água nos alimentos e estão relacionadas entre si. A atividade de água indica a quantidade de água disponível para as reações bioquímicas, físico-químicas e enzimáticas necessárias para o desenvolvimento de microrganismos, assim como para a produção de toxinas (JAY, 1994). Dessa forma, o teor de água do produto constitui um importante fator para sua conservação, pois a redução no teor de água torna o ambiente desfavorável ao crescimento e à multiplicação de microrganismos deteriorantes e toxigênicos (SIQUEIRA, 1995).

Ao final de 25 dias de processamento, observou-se que o embutido controle mostrou a maior atividade de água entre os tratamentos (Figura 2), embora os valores de atividade de água tenham se apresentado próximos entre si, não havendo diferença estatística significativa de $5 \%$.
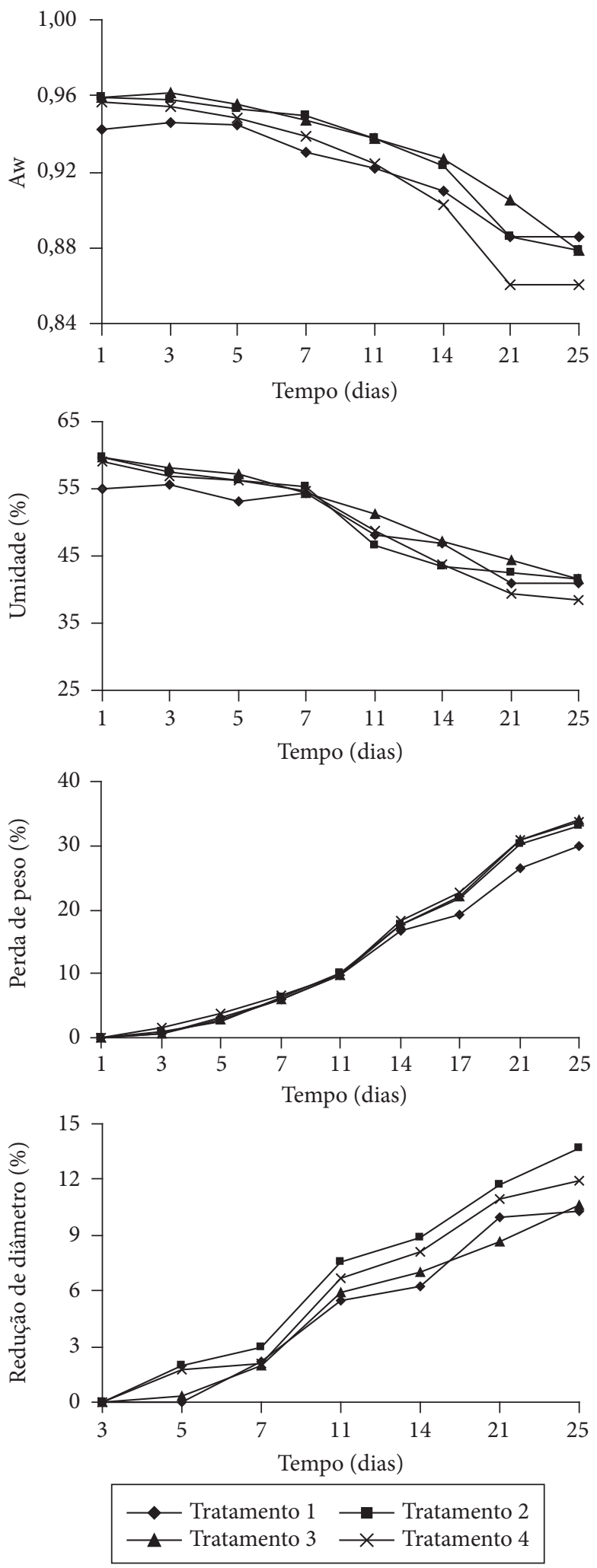

Figura 2. Valores de atividade de água, umidade, perda de peso e redução de diâmetro dos embutidos fermentados em 25 dias de processamento. Tratamento 1: controle (starter); Tratamento 2: Lactobacillus casei + starter; Tratamento 3: Lactobacillus casei ssp. rhamnosus + starter; e Tratamento 4: Lactobacillus paracasei ssp. paracasei + starter. 
O tratamento controle obteve valor de atividade de água de 0,886 , enquanto que os demais tratamentos mostraram valores de $0,879,0,878$ e 0,860 para os Tratamentos 2,3 e 4 , respectivamente. Esses valores encontram-se abaixo do valor máximo de atividade de água de 0,90, recomendado pela legislação brasileira para o salame tipo italiano (BRASIL, 2000), próximos ao valor de 0,88 encontrado por Garcia, Gagleazzi e Sobral (2000) e ao valor de 0,87 citado por Terra (2003), para garantir a segurança microbiológica do salame tipo italiano, visto que a atividade de água mostra-se como o fator mais importante para a conservação da maioria dos embutidos crus fermentados (MONFORT, 2002).

Relacionando a atividade de água com a perda de peso e a redução de diâmetro, verificou-se que o tratamento controle mostrou menores perdas de peso e redução de diâmetro, apresentando valores que diferiram estatisticamente a $5 \%$ de significância dos valores obtidos para os demais tratamentos. Essa condição está relacionada ao maior valor de $\mathrm{pH}$ encontrado para o embutido do tratamento controle, que proporcionou menor perda de água do produto durante o processamento, haja vista que o $\mathrm{pH}$ é um dos principais fatores que influenciam na difusão da água do interior para a superfície do embutido (PINTO; PONSANO; HEINEMANN, 2001).

Coelho et al. (2000) encontraram valores de umidade para o salame tipo italiano de 42,29\%, enquanto que Campos (2002) obteve valores de umidade que variaram entre 38,7 a 43,6\% e Garcia, Gagleazzi e Sobral (2000) obtiveram teor de 36\% para o salame tipo italiano. Os valores de umidade obtidos para os embutidos após 25 dias de maturação foram 40,85, 41,47, 41,48 e 38,54\% para os Tratamentos 1, 2, 3 e 4, respectivamente, mostrando-se dentro da faixa de umidade encontrada em salames tipo italiano.

A determinação da perda de peso é uma medida que mostra indiretamente a quantidade de água eliminada pelo embutido durante o período de secagem e depende da temperatura, umidade relativa no interior da câmara de maturação e do tempo de processamento (GARCIA; GAGLEAZZI; SOBRAL, 2000).

Coelho et al. (2000) citam que o salame tipo italiano pode perder até $40 \%$ de seu peso durante o processamento. A perda de peso encontrada para os embutidos dos Tratamentos 1, 2, 3 e 4 foi de $29,94,33,04,34,08$ e 33,84\%, respectivamente, mostrando que os embutidos com culturas probióticas apresentaram perdas de peso semelhantes, cujos valores mostraram diferença estatística significativa em relação à perda de peso verificada no tratamento controle ( $\mathrm{p} \leq 0,05)$.

A maior perda de peso obtida para os tratamentos adicionados de culturas probióticas está relacionada à acidificação muito intensa da massa, que facilita a quebra de peso dos embutidos. Garcia, Gagleazzi e Sobral (2000) obtiveram perda de peso de $44 \%$ para salame tipo italiano após 20 dias de processamento. Erkkilä et al. (2001a) obtiveram perda de peso de $40 \%$ em salames fermentados por culturas de L. rhamnosus após 28 dias de processamento, cujo valor mostrou-se acima do valor encontrado para o Tratamento 3.

Para a redução de diâmetro verificou-se que o menor valor foi obtido para o tratamento controle. Embora o Tratamento 2
(L. casei) tenha apresentado valores de perda de peso, umidade e atividade de água próximos ao do Tratamento 3, sua redução de diâmetro mostrou-se superior. Essa condição pode ter sido causada pelo encolhimento desuniforme da superfície da peça durante a secagem, ocasionando diferenças na medida do diâmetro.

\subsection{Análises microbiológicas}

As bactérias probióticas apresentaram crescimento no ambiente cárneo, com aumento no número de células viáveis nos primeiros dias de fermentação, como pode ser visualizado na Figura 3. Sameshima et al. (1998) verificaram que o número de células viáveis de L. rhamnosus e L. paracasei em salame mostrou-se próximo a $1 \times 10^{8} \mathrm{UFC}^{-g^{-1}}$ após 3 dias de fermentação a $20^{\circ} \mathrm{C}$. A contagem inicial verificada para L. casei, L. rhamnosus e L. paracasei nos embutidos fermentados foi de $1 \times 10^{7}, 1,1 \times 10^{8}$ e 1,6 X $10^{8}$ UFC.g ${ }^{-1}$, observando-se o aumento desses valores para $3,9 \times 10^{8}, 5,5 \times 10^{8}$ e $4,2 \times 10^{8} \mathrm{UFC}^{-1}$, respectivamente, $^{-}$ no terceiro dia de fermentação.

A partir do sétimo dia, os Lactobacillus mostraram ligeira redução no número de células, porém mantendo valores acima de $10^{6}$ UFC.g ${ }^{-1}$, mínimo recomendado para efeito probiótico, até o final do processamento (FERREIRA, 2003). O número final de células viáveis obtido para L. paracasei foi de $9,5 \times 10^{7}$, para $L$. rhamnosus $5,5 \times 10^{7}$ e para $L$. casei $3,45 \times 10^{7}$, havendo diferença significativa de $5 \%$ entre os tratamentos.

A contagem de P. pentosaceus nos embutidos não sofreu interferência negativa pela presença das culturas probióticas. Nos embutidos que receberam a adição dos Lactobacillus probióticos, o número de células viáveis da bactéria láctica da cultura starter mostrou-se superior ao valor encontrado para o tratamento controle para a maioria dos períodos de tempo avaliados.

A presença das culturas probióticas provocou intensa redução no pH dos embutidos, gerando também redução no número de células de $S$. xylosus da cultura starter, haja vista que valores de $\mathrm{pH}$ inferiores a 5,7 afetam negativamente o desenvolvimento desse microrganismo (STAHNKE, 1995). Na presença dos lactobacilos, a contagem de $S$. xylosus mostrou número de células viáveis inferior a $10^{3} \mathrm{UFC} \cdot \mathrm{g}^{-1}$ a partir do sétimo dia de fermentação, enquanto que no tratamento controle a população de $S$. xylosus manteve-se mais estável, exibindo redução gradativa no número de células durante os 25 dias de processamento. Resultados semelhantes foram obtidos por Papamanoli et al. (2003) em embutido grego fermentado após 27 dias de processamento, no qual a contagem de microrganismos da família Micrococcaceae mostrou-se inferior a $10^{3} \mathrm{UFC}^{-1} \mathrm{~g}^{-1}$, devido ao baixo $\mathrm{pH}$ alcançado pelo produto, com valores próximos a 4,5.

Os microrganismos da família Micrococcaceae utilizados na cultura starter auxiliam na coloração, sabor e aroma dos embutidos. Contribuem na coloração devido à atividade das enzimas nitrato redutase e catalase, importantes para a formação e estabilidade da cor, além de prevenirem a oxidação lipídica. Porém, em condições de baixo $\mathrm{pH}$, sua quantidade é drasticamente reduzida, podendo haver morte das células após o início da fermentação (TERRA; FRIES; TERRA, 2004). Pinto, Ponsano e Heinemann (2001) relatam que para que haja 
a formação da cor típica de produtos curados é necessário que o nitrato adicionado à carne sofra redução a nitrito através da ação da enzima nitrato redutase. As bactérias da família Micrococcaceae têm papel fundamental na redução do nitrato,
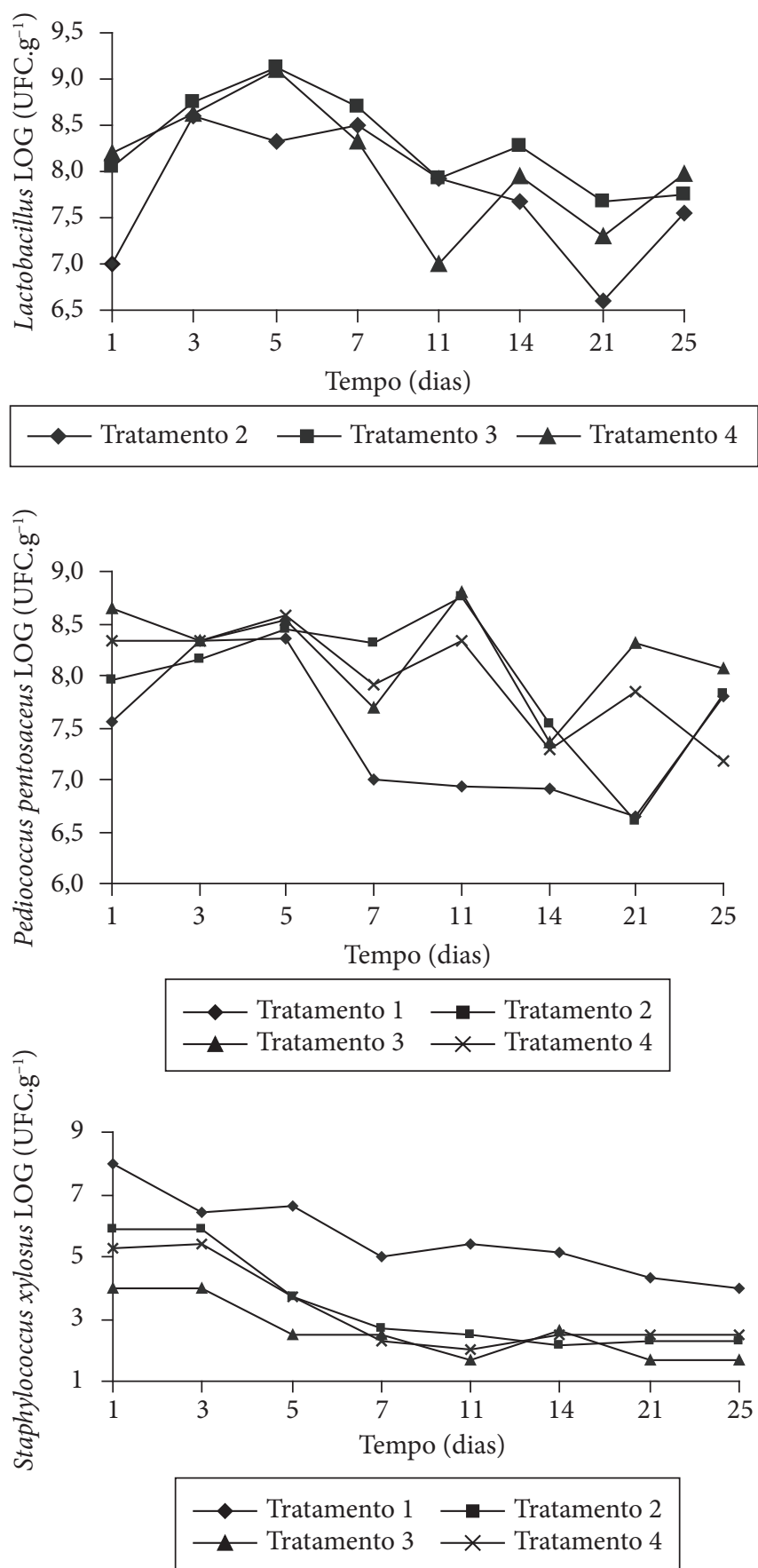

Figura 3. Contagem dos Lactobacillus probióticos, Pediococcus pentosaceus e Staphylococcus xylosus durante o processamento dos embutidos fermentados. Tratamento 1: controle (starter); Tratamento 2: Lactobacillus casei + starter; Tratamento 3: Lactobacillus casei ssp. rhamnosus + starter; e Tratamento 4: Lactobacillus paracasei ssp. paracasei + starter. O número de células viáveis de Lactobacillus no Tratamento 1 não foi determinado. porém sua ação é bastante reduzida em valores de $\mathrm{pH}$ menores que 5,4. Dessa forma, uma redução muito rápida do $\mathrm{pH}$ no início do processamento dos produtos cárneos pode interferir na obtenção da cor avermelhada característica. De acordo com Terra, Fries e Terra (2004), valores de pH inferiores a 4,9 são considerados prejudiciais para o desenvolvimento da cor nos produtos cárneos.

Apesar da importância da família Micrococcaceae na cor, sabor e aroma dos embutidos, o reduzido número de células viáveis de $S$. xylosus observado nos embutidos adicionados de culturas probióticas pareceu não afetar sensorialmente essas características quando comparados ao tratamento controle, pois as pontuações recebidas pelos embutidos dos Tratamentos $2,3 \mathrm{e}$ 4 não apresentaram diferença estatística significativa $(\mathrm{p} \leq 0,05)$ para os atributos de cor, sabor e aroma em comparação às pontuações do tratamento controle.

\subsection{Avaliação sensorial}

Entre os atributos avaliados, verificou-se diferença significativa de $5 \%$ entre os tratamentos somente para o gosto ácido. As pontuações atribuídas pelos provadores para o gosto ácido dos embutidos confirmam os resultados obtidos nas determinações de pH e acidez, que mostraram maior acidez para os Tratamentos 2, 3 e 4. Para esse atributo, as notas mais próximas a 9,0 indicam maior acidez ao paladar, enquanto que as notas mais próximas a 1,0 indicam pouca acidez do embutido (Figura 4).

O embutido controle apresentou gosto ácido menos pronunciado do que os embutidos adicionados de culturas

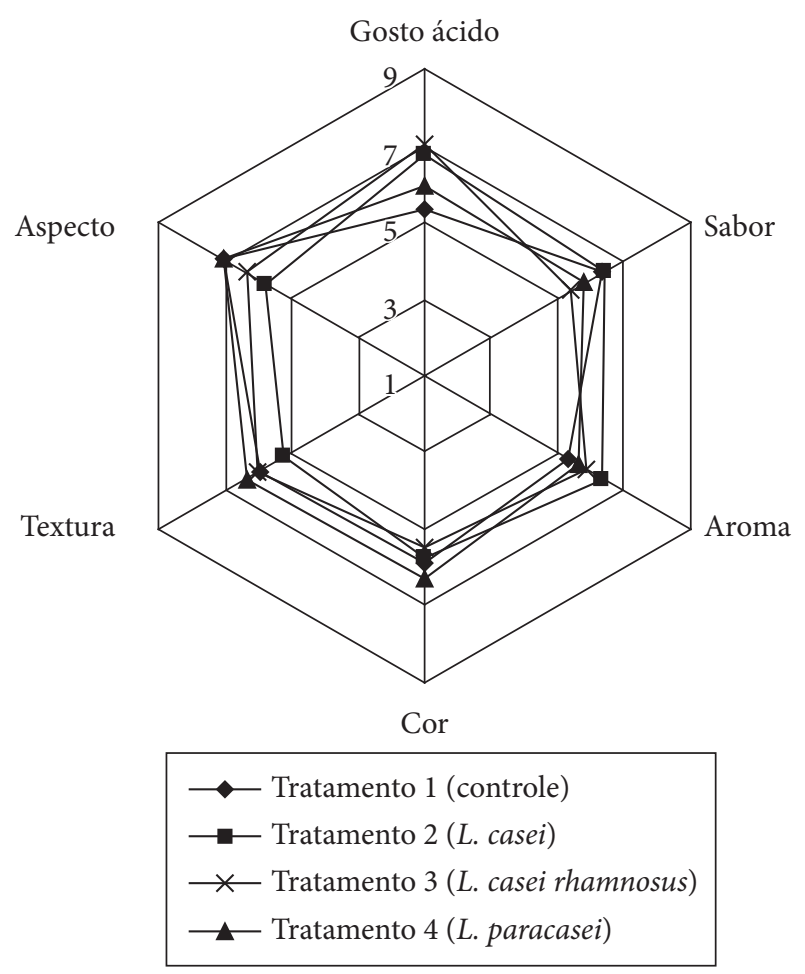

Figura 4. Perfil de características dos embutidos fermentados após 25 dias de processamento. 
probióticas, verificando-se diferença estatística de 5\% de significância entre o controle e os tratamentos que receberam a adição de L. casei (Tratamento 2) e de L. casei ssp. rhamnosus (Tratamento 3).

Entre os tratamentos que receberam as culturas probióticas, o embutido contendo L. paracasei (Tratamento 4) apresentou gosto ácido menos pronunciado, obtendo para esse atributo pontuação próxima à do tratamento controle.

O embutido adicionado de L. rhamnosus (Tratamento 3) mostrou intenso gosto ácido, característica que afetou também sua pontuação para o sabor, para o qual o referido tratamento recebeu a menor nota, visto que o gosto ácido é um componente importante do sabor total dos produtos cárneos fermentados (TERRA; FRIES; TERRA, 2004).

As maiores pontuações para o sabor foram obtidas pelos embutidos do tratamento controle e do tratamento contendo L. casei. Este último também obteve a maior pontuação para o aroma, sendo que o tratamento controle recebeu a menor nota para esse atributo (Figura 4). A sensação de sabor é causada primariamente por compostos não voláteis interagindo com a superfície da língua, enquanto que a sensação do aroma é causada por voláteis que evaporam do alimento durante o processo da mastigação e alcançam a cavidade nasal, onde reagem com receptores olfativos (TERRA; FRIES; TERRA, 2004).

O embutido adicionado de L. paracasei (Tratamento 4) mostrou coloração avermelhada mais intensa e textura mais firme em comparação com os demais, apresentando também menor $\mathrm{pH}$ final, menor teor de umidade e menor atividade de água. Essa condição proporcionou maior firmeza ao embutido, permitindo uma estrutura sólida propícia ao fatiamento (CORETTI, 1971). A capacidade de fatiabilidade do embutido cárneo ocorre pela combinação da formação do gel, devido à acidificação das proteínas solubilizadas pelo sal, seguida da secagem (TERRA; FRIES; TERRA, 2004).

Observou-se que o Tratamento 3 (L. rhamnosus) recebeu a menor pontuação para a cor, seguido pelo Tratamento 2 e pelo Tratamento 1. No entanto, a textura apresentada pelo embutido adicionado de L. rhamnosus (Tratamento 3) mostrou-se mais firme do que aquela apresentada pelo embutido adicionado de L. casei (Tratamento 2).

A aparência geral ou aspecto representa o conjunto de todas as demais características avaliadas reunidas num único atributo. Para o aspecto geral, os Tratamentos 1 e 4 receberam as maiores pontuações, mostrando-se bem apreciados pelos provadores, considerando que a escala utilizada apresentava escore máximo de 9 pontos.

Embora tenham recebido menor pontuação do que os Tratamentos 1 e 4, os Tratamentos 2 e 3 também foram considerados agradáveis pelos julgadores, pois obtiveram pontuações acima de 5,0.

Andersen (1998) verificou que a adição das culturas probióticas L. casei, L. acidophilus e Bifidobacterium lactis ao salame não influenciou negativamente suas características de sabor e aroma, enquanto Pidcock, Heard e Henriksson (2002) relataram que a adição de L. acidophilus, L. paracasei e B. lactis em salame não mostrou impacto negativo sobre suas propriedades sensoriais.

$\mathrm{Na}$ avaliação sensorial, o embutido adicionado de L. paracasei apresentou características bem apreciadas pelos julgadores, mostrando as maiores pontuações para aspecto geral, textura, cor e gosto ácido pouco pronunciado. Por outro lado, o embutido contendo L. casei apresentou melhor sabor e aroma. Ammor e Mayo (2007) afirmam que as culturas probióticas ideais para uso em produtos cárneos fermentados são aquelas que não interferem negativamente nas propriedades tecnológicas e sensoriais dos produtos.

\section{Conclusões}

Os embutidos que receberam a adição das culturas de Lactobacillus mostraram redução mais rápida do $\mathrm{pH}$ durante o processamento, devido à atividade fermentativa desses microrganismos associada à acidificação gerada pelas bactérias lácticas da cultura starter. Essa maior redução de $\mathrm{pH}$ verificada nos embutidos adicionados de culturas probióticas influenciou a acidez sensorial dos produtos, que apresentaram gosto notadamente mais ácido do que o tratamento controle, principalmente o tratamento que recebeu a adição de L. rhamnosus, sendo essa a principal influência sensorial verificada pela adição das culturas probióticas aos embutidos. Para os demais atributos, o uso das culturas probióticas pareceu não afetar positiva ou negativamente as características sensoriais dos embutidos, pois estes se mostraram apreciados pelos provadores.

A adição de L. casei, L. rhamnosus e L. paracasei aos embutidos provocou redução no desenvolvimento de $S$. xylosus. Por outro lado, a presença das culturas probióticas não interferiu no crescimento de $P$. pentosaceus que, para a maioria dos períodos de avaliação, mostrou melhor desenvolvimento quando em conjunto com os Lactobacillus.

No presente experimento, ficou demonstrada a viabilidade da utilização das culturas probióticas de Lactobacillus testadas em embutido cárneo fermentado, principalmente L. paracasei e L. casei, preservando as características tecnológicas e sensoriais de qualidade do produto.

\section{Referências bibliográficas}

AMMOR, M.; MAYO, B. Selection criteria for lactic acid bacteria to be used as functional starter cultures in dry sausage production: An update. Meat Science, v. 76, n. 1, p. 138-146, 2007.

ANDERSEN, L. Fermented dry sausages produced with the admixture of probiotic cultures. In: International Commitment of Meat Science and Technology, 44, 1998, Barcelona. Anais... Barcelona: Institut de Recerca i Tecnologia Agroalimentaries, 1998. p. 826-827.

AOAC. Official methods of analysis of the Association of Official Analytical Chemists. 17 ed. Gaithersburg, 2000. v. 1.

ARIHARA, K. et al. Lactobacillus acidophilus group lactic acid bacteria applied to meat fermentation. Journal of Food Science, Chicago, v. 63, p. 544-547, 1998.

ATCC. American Type Culture Collection. The Global Bioresource Center. Product Description. Disponível em: <http://www.atcc. $\mathrm{org} / \mathrm{common} /$ catalog/numSearch/numResults.cfm $>$ Acesso em: 20 abr. 2005. 
BEJDER, H. C. Probiotics: today dairy, tomorrow the world. Odense: Danish Dairy \& Food Industry, set. 2004. v. 14, p. 42-43.

BRASIL. Ministério da Agricultura, Pecuária e do Abastecimento. Secretaria de Defesa Agropecuária. Instrução Normativa nº 22, de 31 de julho de 2000. Aprova o Regulamento Técnico de Identidade de Qualidade de Salames. Diário Oficial da União, Brasília, 03 ago. 2000. p. 15-28.

BRASIL. Ministério da Saúde. Agência Nacional de Vigilância Sanitária. Resolução RDC no 2, de 07 de janeiro de 2002. Aprova o Regulamento Técnico de Substâncias Bioativas e Probióticos Isolados com Alegação de Propriedades Funcional e ou de Saúde. Diário Oficial da União, Brasília, 09 jan. 2002.

BRASIL. Ministério da Agricultura, Pecuária e do Abastecimento. Secretaria de Defesa Agropecuária. Instrução Normativa no 62, de 26 de agosto de 2003. Oficializa os Métodos Analíticos Oficiais para Análises Microbiológicas para Controle de Produtos de Origem Animal e Água. Diário Oficial da União, Brasília, 18 set. 2003. p. 14.

CAMPOS, R. M. L. Influência da alimentação na qualidade da carcaça suína e do pernil para a fabricação do salame tipo italiano. Santa Maria, 2002. Dissertação - (Mestrado em Ciência e Tecnologia dos Alimentos), Universidade Federal de Santa Maria.

CARR, F. J.; CHILL, D.; MAIDA, N. The lactic acid bacteria: A literature survey. Critical Reviews in Microbiology, v. 28, n. 4, p. 281-370, 2002.

CHAGAS, S. S. Redução do tempo de fabricação do salame tipo italiano. Santa Maria, 1998. Dissertação - (Mestrado em Ciência e Tecnologia dos Alimentos), Universidade Federal de Santa Maria.

CHAVES, J. B. P.; SPROESSER, R. L. Práticas de laboratório de análise sensorial de alimentos e bebidas. Viçosa: Imprensa Universitária da UFV, 1993.

COELHO, H. S. et al. Características físico-químicas do salame tipo italiano contendo couro suíno cozido. Revista Nacional da Carne, n. 278, p. 84-96, abr. 2000.

CORETTI, K. Embutidos: elaboración y defectos. Zaragoza: Acribia, 1971.

DE MAN, J. C.; ROGOSA, M.; SHARPE, M. E. A medium for the cultivation of lactobacilli. Journal of Applied Bacteriology, v. 23, p. 130-135, 1960.

DUTCOSKI, S. D. Análise sensorial de alimentos. 2 ed. Curitiba: Champagnat, 2007. 239 p.

ERKKILÄ, S. et al. Dry sausage fermented by Lactobacillus rhamnosus strains. International Journal of Food Microbiology, Oxford, v. 64, n. 1-2, p. 205-210, 2001a.

ERKKILÄ, S. et al. Flavour profiles of dry sausages fermented by selected novel meat starter cultures. Meat Science, v. 58, p. 111$116,2001 b$.

FERREIRA, C. L. L. F. Grupo de bactérias lácticas - Caracterização e aplicação tecnológica de bactérias probióticas. In: Prebióticos e Probióticos: Atualização e Prospecção. Viçosa: Célia L. L. F. Ferreira, 2003. 206 p.

GARCIA, F. T.; GAGLEAZZI, U. A.; SOBRAL, P. J. A. Variação das propriedades físicas e químicas do salame tipo italiano durante secagem e fermentação. Brazilian Journal of Food Technology, Campinas, v. 3, n. 48, p. 151-158, 2000.

GOMES, F. P. Curso de estatística experimental. 13 ed. Piracicaba: Escola Superior de Agricultura Luiz de Queiroz - USP, 1990.

HEENAN, C. N.; ADAMS, M. C.; HOSKEN, R. W. Growth medium for culturing Probiotics bacteria for applications in vegetarian food products. Lebensmittel-Wissenschaft und Technologie, Oxford, v. 35, n. 2, p. 171-176, 2002.

JAY, J. Microbiología Moderna de los Alimentos. 3 ed. Zagaroza: Acribia, 1994. p. 804

LEROY, F.; VERLUYTEN, J.; VUYST, L. Functional meat starter cultures for improved sausage fermentation. International Journal of Food Microbiology, v. 106, n. 3, p. 270-285, 2006.

LÜCKE, F. K. Utilization of microbes to process and preserve meat. Meat Science, v. 56, n. 2, p. 105-115, 2000.

MAHONEY, M.; HENRIKSSON, A. The effect of processed meat and meat starter cultures on gastrointestinal colonization and virulence of Listeria monocytogenes in mice. International Journal of Food Microbiology, v. 84, n. 3, p. 255-261, 2003.

MONFORT, J. M. Los productos carnicos crudos curados. In: CONGRESSO BRASILEIRO DE CIÊNCIA E TECNOLOGIA DE ALIMENTOS, 18, 2002, Porto Alegre. Anais... Porto Alegre: SBCTA, 2002. p. 3984-3992.

MORAES, M. A. C. Métodos para avaliação sensorial de alimentos. 7 ed. Campinas: UNICAMP, 1990.

MUTHUKUMARASAMY, P.; HOLLEY, R. A. Microbiological and sensory quality of dry fermented sausages containing alginatemicroencapsulated Lactobacillus reuteri. International Journal of Food Microbiology, v. 111, n. 2, p. 164-169, 2006.

NASSU, R. T.; BESERRA, F. J.; GONÇALVES, L. A. G. Processo Agroindustrial: obtenção de embutido fermentado tipo salame de carne de caprinos. Comunicado Técnico, n. 74. Fortaleza: EMBRAPA, dez. 2002.

PAPAMANOLI, E. et al. Characterization of lactic acid bacteria isolated from a Greek dry-fermented sausage in respect of their technological and probiotic properties. Meat Science, v. 65, n. 2, p. $859-867,2003$.

PIDCOCK, K.; HEARD, G. M.; HENRIKSSON, A. Application of nontraditional meat starter cultures in production of Hungarian salami. International Journal of Food Microbiology, v. 76, n. 1-2, p. 75-81, 2002.

PINTO, M. F.; PONSANO, E. H. G.; HEINEMANN, R. J. B. Bactérias envolvidas no processamento de produtos cárneos - uma revisão. Boletim do SBCTA, v. 35, n. 1-2, p. 109-116, 2001.

SANT’ANA, A. S.; CONCEIÇÃO, C.; AZEREDO, D. R. P. Comparação entre os métodos Simplate TPC-CI e Petrifilm AC e os métodos convencionais de contagem em placas para a enumeração de aeróbios mesófilos em sorvete. Ciência e Tecnologia de Alimentos, Campinas, v. 22, n. 1, p. 60-64, 2002.

SAMESHIMA, T. et al. Effect of intestinal Lactobacillus starter cultures on the behaviour of Staphylococcus aureus in fermented sausage. International Journal of Food Microbiology, v. 41, n. 1, p. 1-7, 1998.

SILVA, N.; JUNQUEIRA, V. C. A.; SILVEIRA, N. F. A. Manual de métodos de análise microbiológica de alimentos. 2 ed. São Paulo: Livraria Varela, 2001. 317 p.

SIQUEIRA, S. Manual de microbiologia de alimentos. Brasília: Embrapa, 1995. 159 p.

STAHNKE, L. H. Dried sausages fermented with Staphylococcus xylosus at different temperatures and with different ingredient levels - Part I. Chemical and bacteriological data. Meat Science, v. 41, n. 2, p. 179-191, 1995.

SWANSON, K. M. et al. Colony Count Methods. In: VANDERZANT, C.; SPLITTSTOESSER, D. F. Compendium of methods for the microbiological examination of foods. 3 ed. Washington: American Public Health Association, 1992. p. 75-96. 
TERRA, N. N.; BRUM, M. A. R. Carne e seus derivados. Técnicas de controle de qualidade. São Paulo: Nobel, 1988. 121 p.

TERRA, N. N. Apontamentos de Tecnologia de Carnes. São Leopoldo: UNISINOS, 1998. $216 \mathrm{p}$.

TERRA, N. N. Particularidades na fabricação do salame. Revista Nacional da Carne, São Paulo, n. 317, julho, 2003. Disponível em:<http://www.dipemar.com.br/carne.htm> Acesso em: 19 abr. 2005.

TERRA, A. B. M.; FRIES, L. L. M.; TERRA, N. N. Particularidades na fabricação de salame. São Paulo: Livraria Varela, 2004. 152 p.

TYÖPPÖNEN, S.; PETÄJÄ, E.; MATTILA-SANDHOLM, T. Bioprotectives and probiotics for dry sausages. International Journal of Food Microbiology, v. 83, n. 3, p. 233-244, 2003. 